\title{
Sodium reduction in crackers: optimization of process to keep sensory quality without
}

\section{technological impacts}

\author{
Fabiana Pieta ${ }^{1}$, Adriana Pieta ${ }^{\oplus}$, Caroline Marques ${ }^{2} \odot$, Vânia de Cássia da Fonseca Burgardt ${ }^{3}$, Naimara Vieira do Prado ${ }^{4 \oplus}$, \\ Alessandra Machado-Lunkes ${ }^{5}{ }^{\circ}$, Luciano Lucchetta $^{3 *}{ }^{*}$
}

'Kellogg's Parati, R. Tiradentes, 475 - 89990-000 - São Lourenço do Oeste, SC - Brasil.

2Universidade Federal do Paraná - Depto. de Engenharia Química, Av. Francisco Heráclito dos Santos, 100 - 81531 980 - Curitiba, PR - Brasil.

3Universidade Tecnológica Federal do Paraná - Depto. de Ciências Agrárias, Campus Francisco Beltrão, C.P. 135 85601-971 - Francisco Beltrão, PR - Brasil.

4Universidade Tecnológica Federal do Paraná - Depto. de Física, Estatística e Matemática, Campus Francisco Beltrão, C.P. 135 - 85601-971 - Francisco Beltrão, PR - Brasil. 5Universidade Tecnológica Federal do Paraná - Depto. de Química, Bioquímica e Biologia, Campus Francisco Beltrão, C.P. 135 - 85601-971 - Francisco Beltrão, PR - Brasil. *Corresponding author <lucchetta@utfpr.edu.br>

Edited by: Luís Guilherme de Lima Ferreira Guido

Received October 19, 2020

Accepted February 20, 2021
ABSTRACT: Excess sodium in foods is one of the factors in chronic non-communicable diseases whose importance is on the rise. Thus, the aim of this study was to optimize a replacement for sodium in an appetizer-type Mignon cracker on an industrial scale. For this, a mixture design consisting of seven formulations were prepared with sodium replacement ranging between 30 and $60 \%$. The partial sodium replacement used industrial ingredients (Nutek Salt and PuraQ NA4, and modified $\mathrm{KCl}$ and flavor), to assess the impact on sodium content and texture (hardness). No significant differences were found in the hardness attribute. Sodium reduction

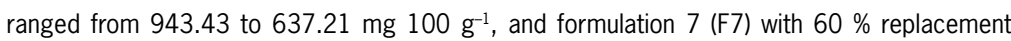
could cash in on the "Reduced in sodium" appeal. A sensory Quantitative Descriptive Analysis accessed the sensory profiles of formulations, and significant differences were observed $(p<$ 0.05 ) in salty taste, sweet taste, bread aroma, and formulation 4 (40\% replacement) but were not significantly different from the formulation in salty taste. In PCA, the first main component showed variability between samples of $84.6 \%$, while the second axis explained $11.5 \%$ of this variability. Acceptance (taste and overall quality) and purchase intention (above $>70 \%$ ) showed that the substitution did not affect consumers' perceptions, with no significant difference between controls, F4 and F7.

Keywords: baked products, salt, texture, acceptance, upscale

\section{Introduction}

The consumption of processed and/or industrialized foods and sedentary lifestyle, favors the occurrence of chronic non-communicable diseases known as CNCDs, among which the most common are diabetes, cardiovascular diseases and obesity (Benziger et al., 2016; WHO, 2002, 2010). It is estimated that hypertension is responsible for the deaths of nine million people per year worldwide and governments aiming to reduce these numbers, recommend reductions in sodium intake (Kitt et al., 2019; WHO, 2016).

The majority of consumers understand the importance of controlling sodium intake (Benincá et al., 2018). Sodium reduction is based on the direct reduction or use of $\mathrm{NaCl}$ substitute salts and other ingredients. This approach is very modern and is widely applied to the reduction of sodium in cheeses, meats and culinary preparations (Di Domenico et al., 2020; Hoffmann et al., 2020; Santos et al., 2020; Vidal et al., 2020).

Many salt substitutes available on the market use $\mathrm{KCl}$ as the main ingredient, as it has a salting capacity very similar to $\mathrm{NaCl}$. However, $\mathrm{KCl}$ has a bitter taste which is an inconvenience for the food industry (Cepanec et al., 2017). A solution currently on offer to the industry is modified potassium chloride, called Nutek Salt, whose main characteristic is the absence of residual bitter taste. Crystals of modified potassium chloride called Nutek Salt have proven to be a plausible alternative with the potential to replace up to $50 \%$ of sodium chloride (Kanellos, 2012).

Alternative strategies try to develop compounds that enhance the salty taste through the presence of different combinations of molecules, as protein derivatives, modified salts, fermentation compounds and aromas. Certain solutions available in this area also use spices, herbs and yeast hydrolyzate (Taylor et al., 2018). PuraQ NA4 is another of the innovative options developed by the industry of sodium replacement ingredients. This product reduces sodium chloride by up to 30 \% (Corbion Puraq, 2013; Seganfredo et al., 2016).

Cracker is a baked product consumed by all age groups and social classes of people, and has a wide variation of ingredients to meet the needs and expectations of different consumers' profiles (Chavan et al., 2016; Mesías et al., 2015). Industrialized products such as crackers are widely appreciated and consumed, and together they contribute to more than half of the recommended daily sodium intake (Arepally et al., 2020; Souza et al., 2013). Therefore, the reduction in sodium intake is directly linked to the reduction in sodium by the food industry (FDA, 2016).

Thus, this study aimed to reduce the sodium content in appetizer-type Mignon salty cracker by using flavoring and salt substitutes. To this end, two separate purposes were identified: 1) Formulate different 
crackers using a mixture designed to replace sodium chloride with modified potassium chloride and aroma up to the $60 \%$ substitution level; 2) investigate the physicochemical parameters and sensory characteristics of the sodium-replaced crackers.

\section{Materials and Methods}

\section{Specification}

To reduce sodium content in the crackers, two sodium chloride substitutes were tested: modified potassium chloride, the previously mentioned Nutek Salt, and a flavor, PuraQ NA4. The original formulation, produced by a company established in the state of Santa Catarina (Brazil), was denoted as control formulation. From the original formulation, the other formulations suggested by experimental design are defined in Table 1.

Seven formulations of appetizer-type Mignon salty cracker were constructed according to the mixture design. The cracker has in its composition: wheat flour enriched with iron and folic acid, vegetable fat, sugar, starch, malt extract, soy lecithin, glucose syrup, whey milk powder, micronized salt, chemical yeasts (sodium bicarbonate, ammonium bicarbonate and monocalcium phosphate) and flavoring. On grounds of

Table 1 - Mixture design for limited surfaces. Mixture design\#

\begin{tabular}{lccccccc}
\hline \multirow{2}{*}{ Formulations $^{\# \#}$} & \multicolumn{3}{c}{ Original Components } & & \multicolumn{3}{c}{ Pseudo Components } \\
\cline { 2 - 3 } \cline { 7 - 8 } & X1 & X2 & X3 & & $X^{\prime} 1$ & $X^{\prime} 2$ & $X^{\prime} 3$ \\
\hline 1V (F1) & 0.70 & 0.30 & 0.00 & & 0.50 & 0.50 & 0.00 \\
2V (F2) & 0.70 & 0.00 & 0.30 & & 0.50 & 0.00 & 0.50 \\
4C (F3) & 0.70 & 0.15 & 0.15 & & 0.50 & 0.25 & 0.25 \\
7C (2)*(F4) & 0.60 & 0.20 & 0.20 & & 0.33 & 0.33 & 0.33 \\
5C (F5) & 0.55 & 0.30 & 0.15 & & 0.25 & 0.50 & 0.25 \\
6C (F6) & 0.55 & 0.15 & 0.30 & & 0.25 & 0.25 & 0.50 \\
3V (F7) & 0.40 & 0.30 & 0.30 & & 0.00 & 0.50 & 0.50 \\
\hline
\end{tabular}

\#X1 + X2 + X3 = 1 ou $100 \% ; X 1=\mathrm{NaCl}, \mathrm{X} 2=$ Nutek Salt and X3 = PuraQ NA4; \#\#V = vertex, $C=$ centroide; ${ }^{\star}$ Repetition. secrecy, as prompted by the company holding the brand, percentages of each ingredient that make up the control formulation will not be presented. However, it can be disclosed that the formulation contains $2 \%$ micronized $\mathrm{NaCl}$. Moreover, appetizer-type Mignon salty crackers have a crispy characteristic and a $\mathrm{V}$ format. $\mathrm{NaCl}$ substitutes were used sparingly, as they do not have the same salting power, and may add unpleasant flavors, in addition to being more expensive than $\mathrm{NaCl}$.

\section{Experimental design}

The experimental design consisted of mixtures for limited surfaces obtained through the module in the Statistica $^{\odot} 7.0$ software program with the following variables: $\mathrm{X} 1$ - $\mathrm{NaCl}$ (micronized salt), X2 - modified $\mathrm{KCl}$ (Nutek Salt) and X3 - Flavor (PuraQ NA4). In the control formulation the $\mathrm{NaCl}$ content was $2 \%$, and in all formulations within the minimum and maximum proportions of each of the ingredients, $\mathrm{NaCl}$, together with its substitutes, accounted for $2 \%$ of the total.

The minimum and maximum limits for replacement agents were defined based on information from the manufacturer and previous studies (Bassett et al., 2014; Busch et al., 2013; Souza et al., 2013; Vogel et al. (2011)). Thus, $0 \%$ was the minimum limit and $30 \%$ the maximum. The percentages of substitution transformed into pseudo-components are shown in Table 1 .

\section{Production of crackers}

The crackers were manufactured on an industrial scale. The process was carried out in a continuous production oven and automated system, following the basic steps showed in Figure 1.

\section{Physicochemical assessment of crackers}

All the samples for analysis were collected after the packing stage to ensure there were both sufficient

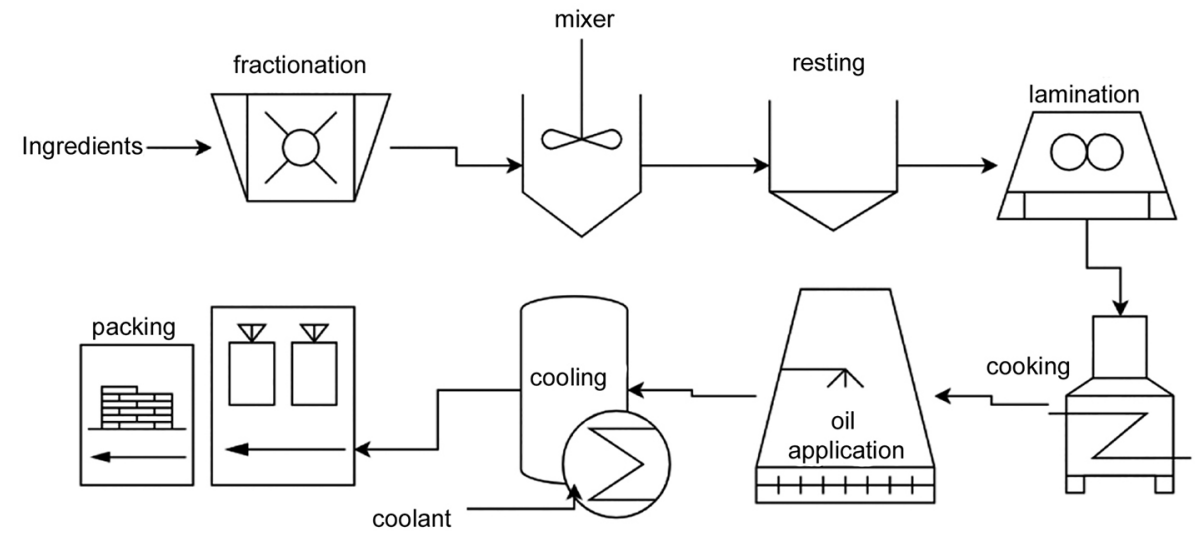

Figure 1 - Flowchart of appetizer-type Mignon cracker's production on industrial scale. 
and representative samples for conducting all the experiments. The sodium content was measured with three repetitions in triplicate, and the hardness in ten repetitions. The crackers were analyzed for sodium content using the optical emission spectrometry with inductively coupled plasma (ICP-OES) (AOAC, 2005) method. The samples were analyzed by Shimatzu ICPOES equipment, Model ICPE-9000 with readings on a wavelength of 589-592 $\mathrm{nm}$ and the results expressed in mg of sodium $100 \mathrm{~g}^{-1}$.

Hardness was determined using a TAX-T texturometer (Stable Micro Systems), knife-edge probe (HDP/BS) with a load of $25 \mathrm{~kg}$ and a platform (HDP/90). The parameters followed in the test were: pretest speed of $1.5 \mathrm{~mm} \mathrm{~s}^{-1}$, test speed of $2 \mathrm{~mm} \mathrm{~s}^{-1}$ and post-test speed $10 \mathrm{~mm} \mathrm{~s}^{-1}$, a distance of $5 \mathrm{~mm}$ according to the BIS2/KB protocol and trigger force of $50 \mathrm{~kg}$ in accordance with the BIS4/3PB protocol (Stable Micro Systems, 2000). Ten replicates were carried out for each treatment, and the results for hardness were obtained in Newton (N).

\section{Sensory evaluation}

The formulations were evaluated following the Quantitative Descriptive Analysis (QDA) method, in addition to the hedonic tests of acceptance, preference and purchase intention. Furthermore, the crackers had been previously subjected to microbiological analyses in order to assure the quality of the prepared product. For the QDA application, all the requirements defined by ISO $2017 \mathrm{a}$, and the methodology described by Stone and Sidel (2004) and Silva et al. (2018) were followed. The Research Ethics Committee (UTFPR), CAEE number 1.361.970, approved this study.

\section{Recruitment and pre-selection of assessors}

Initially, 25 employees of the food company were invited to make up the sensory team, considering that these assessors are already part of the company's sensory analysis panel, meaning, trained in accordance with the requirements of ISO, 2012 (E). Of these 25 assessors, 17 had the availability and interest in participating and demonstrated aptitude in previous tests in color identification, basic tastes and sensitivity to olfactory stimuli.

\section{Assessors' selection}

The 17 participants underwent 10 triangular tests to verify the ability to discriminate between samples differences (ISO, 2017b). The materials and concentrations used for sample preparation followed the indications of ISO, 2012 (E). The materials (Salty - Sodium chloride; Sweet - Sucrose; Metallic - Iron sulfate heptahydrate $\mathrm{FeSO}_{4} \cdot 7 \mathrm{H}_{2} \mathrm{O}$; Texture-Appetizer-type Mignon salty cracker in different textures were diluted in distilled water at room temperature. Wald's sequential analysis was applied to the results, to analyze the assessors' discriminatory capacity (BS ISO, 2004). The acceptance $(\mathrm{Ac})$ and rejection $(\mathrm{Rj})$ plot lines of the sequential test for the selection of assessors were $\mathrm{Ac}=2.085+0.50 \mathrm{n}$ and $\mathrm{Rj}=-1.624+0.50 n$.

\section{Establishing the descriptive terminology}

The evaluation of the samples for a compilation of terms was carried out according to the Grid method (ISO 13299:2016). The samples were presented in pairs, for comparison and description of terms related to appearance, aroma, taste and texture. Consensus training sessions were held with the panel of assessors to define the most appropriate and important terminology, as well as to establish references for each extreme point on the scale.

\section{Final panel selection}

With triangular tests, four training sessions were carried out until the sensory memory of each assessor and uniformity of the placement in the same region of the scale had been formed, through the presentation of reference samples from the extremes of the scales. The training ended when the panel demonstrated that they had no difficulties in evaluating the samples using the evaluation form. In this last stage, of the 17 judges only 10 were selected for appointment to the final QDA panel (6 women and 4 men, aged 22-55 years). The selection of the final QDA panel was carried out with three Mignon cracker formulations (Control, F3 and F7), evaluated in three repetitions, collected before the standardization of the process so the panel could identify differences and the greatest number of attributes.

Analysis of variance (ANOVA) statistically assessed the overall performance of the panel in relation to each attribute in terms of discriminative capacity, consensus and reproducibility. The sample $\left(\mathrm{p}_{\text {sample }}<\right.$ 0.05), expressed the discriminative capacity of the panel, and the intercept effect of "Assessor*Sample" expressed the panel consensus. In addition, the intercepts "Sample*Repetition" and "Assessor*Repetition" stated the reproducibility of the panel. In the intercept $\mathrm{p}_{\text {interactions }}$ > 0.05 (Antmann et al., 2011; Worch et al., 2010) was desirable.

\section{Evaluation of samples}

Quantitative descriptive analysis of Mignon crackers followed ISO, 2017a using ten trained tasters to evaluate all formulations in three repetitions. The intensity of the sensory descriptors (attributes) were assessed via an unstructured 9-cm scale, with intensity terms anchored at their ends, in ascending order of intensity from left to right.

The samples were presented in a sequential monadic manner, in completely randomized blocks, 
in order to reduce bias from the order of the samples. The tests were carried out in individual booths under white light. The assessors received approximately 15 $\mathrm{g}$ of sample, served on disposable plates encoded with three-random digits.

\section{Hedonic assessment}

In the affective tests, the formulations of greatest interest were used, i.e. the formulation with the lowest sodium content, the one with the highest sensory evaluations and similarity to control, in addition to the control sample itself. The acceptance, preference and purchase intent tests were applied at the Company's Sensory Laboratory, in accordance with Meilgaard et al. (2007). One hundred employees [61 women and 39 men, aged $18-30$ years $(41 \%), 31-40$ years $(40 \%), 41-50$ years $(11 \%)$ and 51-60 years (8\%)] which do not have direct contact with the production of crackers.

The assessors were instructed to point out how much they liked or disliked the product in relation to the attributes of interest: taste and overall quality using a 9-point structured hedonic scale ranging from "Like it extremely (9)" to "Dislike it extremely (1)". In the ordering test for preference, weighting 3 is assigned to the most preferred sample, 2 to the next and 1 to the least preferred. In the ordering test for purchase intention, a structured 5 -point scale ranging from "I would certainly buy (5)" to "I would certainly not buy (1)" was applied (García-Gómez et al., 2019; Dutcosky, 2013; Stone and Sidel, 2004).

\section{Statistical analysis}

Shapiro-Wilk Normality Test checked the hypothesis of normality in physicochemical data, subsequent Analysis of Variance (ANOVA) and Tukey test accessed mean differences, using the Statistica ${ }^{\odot} 7.0$ software program, and expressed as averages \pm standard deviation. The Response Surface Methodology was also used to assess the influence of $\mathrm{NaCl}$ and its substitutes on the responses of chemical and physical parameters.

The sensory data were subjected to the Levene test to verify the homogeneity of the variances in addition to the ANOVA and Tukey test. To verify the correlations between the samples and the sensory attributes, the QDA data set was evaluated by Principal Components Analysis (PCA), and the attributes were used as variables, applying covariance $=n-1$, in the XLSTAT $^{\circledR}$ 2014 software program.

The PCA allows for a set of correlated variables to become a set of uncorrelated main components (PCs) (Granato et al., 2018). The new coordinates are obtained from the covariance matrix, X T X, producing the A pairs of eigenvalues and eigenvectors. PCs are extracted so that the maximum amount of data variation is associated with the first PC. For significant PCA results, it is crucial to report factorial loads, factor values and the amount of explained variance. The dominant patterns present in the samples and variables are plotted in the columns of the scoring matrix and the loading matrix, respectively (Granato et al., 2018).

\section{Results and Discussion}

\section{Physicochemical assessment of crackers}

The results showed that $\mathrm{KCl}$ (Nutek) and Aroma (PuraQ NA4) can be used to replace $\mathrm{NaCl}$ and produce a considerable reduction in sodium in Mignontype crackers with minimal impact on sensory and technological quality.

All formulations of the control formulation had a reduction in sodium (Figure 2). The F7 formulation with a value of $637.21 \mathrm{mg} 100 \mathrm{~g}^{-1}$ stands out on account of its lowest content among the formulations. Formulations F4, F5, F6 and F7 had sodium (Na) results

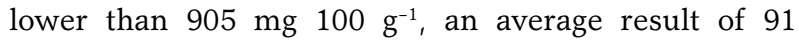
brands of crackers in the salty category (Cream Cracker and similar) found in research carried out by the FDA (FDA, 2016). Furthermore, F4, F5, F6 and F7, can use the term "sodium reduced" on the label, justified by sodium reduction higher than $25 \%$, as established by the Brazilian regulation RDC n. 54 (ANVISA), and only F7 could do the same according to FDA 21CFR101.56 (reduction must exceed $50 \%$ ).

Hardness is a positive and sought-after feature in products with low moisture content, as in the case of salty crackers. The results for hardness (between 22.88 $\mathrm{N}-26.67 \mathrm{~N}$ ) of the formulations, showed no significant differences $(p>0.05)$. This indicated and corroborated that $\mathrm{NaCl}$ removal and addition of replacers had no significant interference in the parameters' moisture and aw of the crackers (see supplementary material).

In bakery products, salt contributes to the hydration of proteins and enhances the bonds between them and fats, promoting the development of the gluten network (Taylor et al., 2018). In the present findings, the decrease in sodium chloride did not interfere in the hardness of crackers.

The response surface for hardness was better represented by the linear adjustment, whereas the sodium content was better represented by the quadratic adjustment. The asterisks presented along with the coefficients of the equation mean that they were significant and not neglected in the equation (Table 2).

The adjustment of data to the model was evident $(p<0.05)$ and no significant missing adjustment was identified $(p>0.05)$, which demonstrated the normality of the data and adequate constant variance of the error (Table 2). The linear adjustment for the hardness parameters, and the quadratic adjustment for the $\mathrm{Na}$ content in terms of pseudo-components (Figure 3A and B), demonstrated that the addition of Nutek Salt (X'2) as well as the increase in $\mathrm{NaCl}\left(\mathrm{X}^{\prime} 1\right)$ contributed to the lowest hardness values. Consequently, the replacement PuraQ NA4, led to an increase in the hardness parameter. 


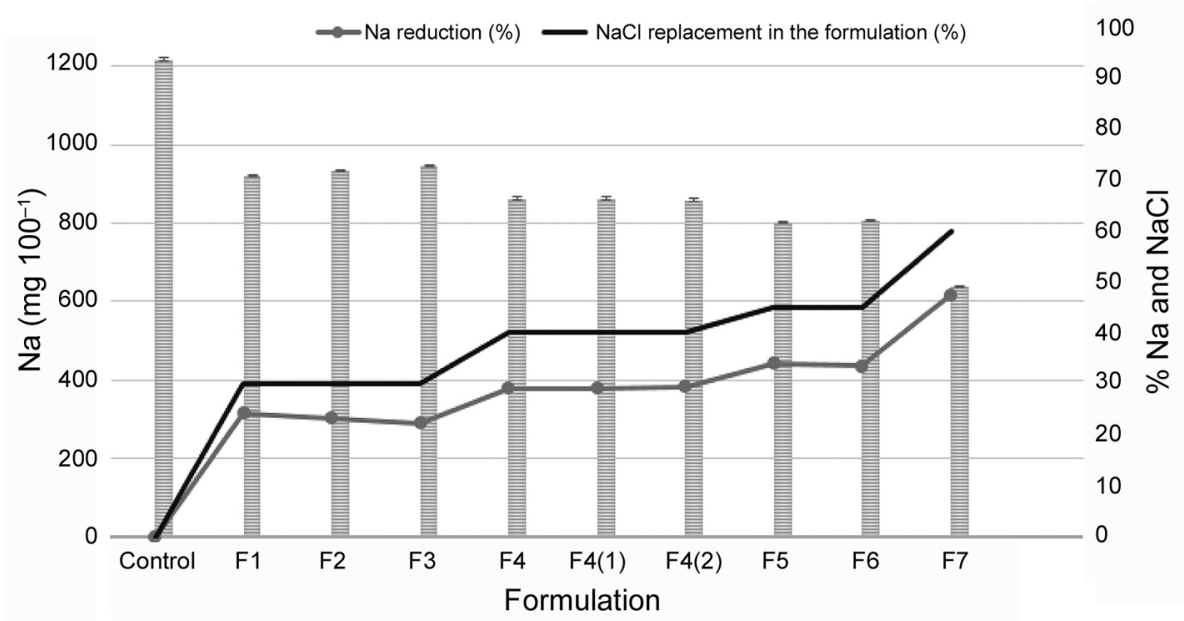

Figure 2 - Reduction in sodium content of the formulations compared to the control formulation.

Table 2 - Values of the coefficients of the linear model for hardness and the quadratic model for sodium content in terms of pseudocomponents, in addition to the ANOVA for the responses.

\begin{tabular}{|c|c|c|c|c|c|}
\hline \multirow{2}{*}{$\begin{array}{l}\text { Parameters } \\
\text { Hardness } \\
\end{array}$} & \multicolumn{5}{|c|}{ PSEUDOCOMPONENTS\# } \\
\hline & X'1 & $x^{\prime} 2$ & X'3 & & \\
\hline \multirow[t]{2}{*}{ Coefficients } & 22.88 & 23.02 & 29.53 & & \\
\hline & * & * & * & & \\
\hline Standard error & 1.202 & 1.202 & 1.202 & & \\
\hline Sodium content & $X^{\prime} 1$ & $X^{\prime} 2$ & $X^{\prime} 1 X^{\prime} 2$ & $X^{\prime} 1 X^{\prime} 3$ & $x^{\prime} 2 X^{\prime} 3$ \\
\hline \multirow[t]{2}{*}{ Coefficients } & 1103.90 & 549.30 & 366.90 & 380.30 & 315.60 \\
\hline & * & * & * & * & * \\
\hline Standard error & 14.673 & 14.673 & 14.673 & 34.910 & 34.910 \\
\hline \multicolumn{6}{|l|}{ ANOVA } \\
\hline Hardness & $\begin{array}{c}\text { SS } \\
\text { (Sum of Squares) }\end{array}$ & $\begin{array}{c}\text { DF } \\
\text { (Degrees of Freedom) }\end{array}$ & $\begin{array}{c}\text { AS } \\
\text { (Average Square) }\end{array}$ & $F$ value & $p$-value \\
\hline Model & 9.08 & 2 & 4.54 & 7.06 & 0.027 \\
\hline Total error & 3.86 & 6 & 0.64 & & \\
\hline Missing adjustment & 2.91 & 4 & 0.73 & 1.54 & 0.431 \\
\hline Error & 0.95 & 2 & 0.47 & & \\
\hline Total adjusted & 12.94 & 8 & 1.62 & & \\
\hline Sodium content & SS & DF & AS & $F$ value & $p$-value \\
\hline Model & 69659 & 5 & 13931.77 & 3451.84 & 0.000 \\
\hline Total error & 12.11 & 3 & 4.04 & & \\
\hline Missing adjustment & 2.69 & 1 & 2.69 & 0.57 & 0.53 \\
\hline Error & 9.42 & 2 & 4.71 & & \\
\hline Total adjusted & 69671 & 8 & 8708.87 & & \\
\hline
\end{tabular}

" $X^{\prime} 1=\mathrm{NaCl}, X^{\prime} 2=$ Nutek Salt, $X^{\prime} 3=$ PuraQ NA4.

This occurred as Nutek Salt contains maltodextrin in its composition, a known water-retention agent (Marcus, 2019) leading to lower hardness values.

To the increase of $\mathrm{Na}$ content, as expected, $\mathrm{X}^{\prime} 1$ made an important contribution, as from the three components it is the only one that contains sodium. The decrease in this parameter was observed as the concentration of the substituents $\mathrm{X}^{\prime} 2$ and $\mathrm{X}^{\prime} 3$ increased, and the combination of both $(0.5)$ promoted the greatest reduction in $\mathrm{Na}$ content, since they do not have sodium in the formulation.

\section{Sensory descriptive analysis}

\section{Establishment of descriptive terminology}

From 17 assessors evaluated in order to compose the final panel, 10 were selected, considered suitable for performing QDA tests. They listed the similarities and differences observed in the samples. The assessors, based on the panel's suggestions (Table 3), established the definition of the descriptive terms and the references for each extreme point on the scale. 
A

Hardness

$\mathrm{R}^{2}=0.702 ; \mathrm{R}_{\text {ajusted }} 0.602$

Hardness $=22.8 \times 1+23.0 \times 2+29.5 \times 3$

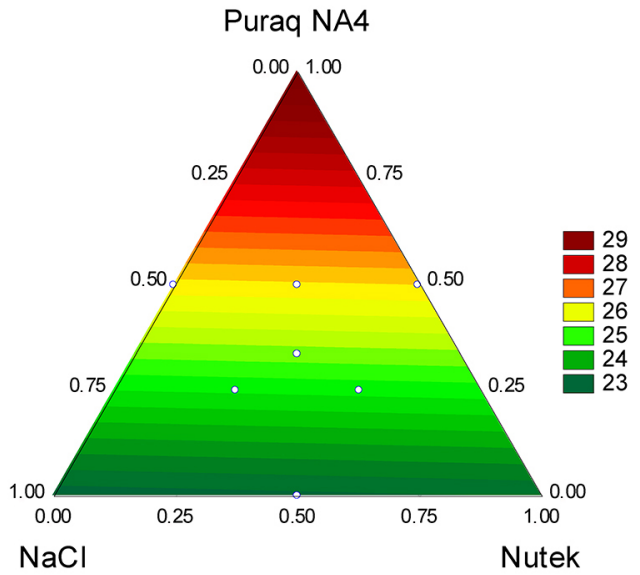

B

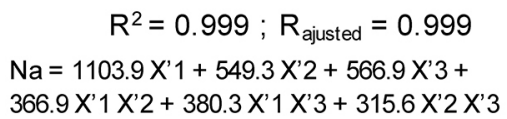

Puraq NA4

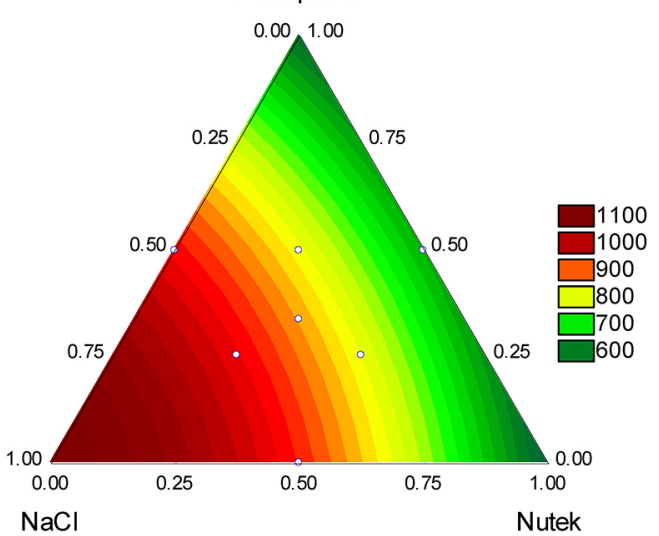

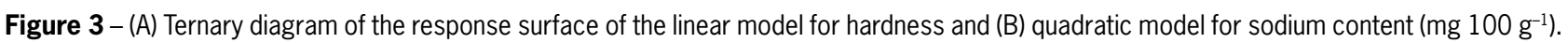

Table 3 - Descriptive terms (attributes) and reference materials for Mignon-appetizer cracker.

\begin{tabular}{|c|c|c|c|}
\hline Attributes & & Definition & Reference \\
\hline \multirow{7}{*}{ 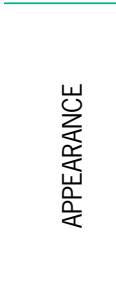 } & Color uniformity & Color homogeneity along the biscuit surface & Little: Brand A Mignon cracker \\
\hline & \multirow[b]{2}{*}{ Roast color } & \multirow[b]{2}{*}{ Color associated with the baking process } & Little: Mignon cracker with -1.5 min cooking. \\
\hline & & & Much: Mignon cracker with + 1.5 min cooking. \\
\hline & \multirow{2}{*}{ Thickness } & \multirow{2}{*}{ Standard cookie height: $6.2 \pm 1 \mathrm{~mm}$} & Little: Brand A Mignon cracker \\
\hline & & & Much: Brand B Mignon cracker \\
\hline & \multirow{2}{*}{ Brightness } & \multirow{2}{*}{ Perception of light reflection intensity } & Little: Brand A Mignon cracker \\
\hline & & & Much: Mignon Cream cracker Parati ${ }^{\odot}$ \\
\hline \multirow{4}{*}{$\begin{array}{l}\sum_{0}^{\mathbb{a}} \\
\frac{1}{<}\end{array}$} & Roast aroma & Aroma associated with the baking process & $\begin{array}{l}\text { Weak: Brand A water and salt cracker } \\
\text { Intense: Brand B water and salt cracker }\end{array}$ \\
\hline & \multirow{2}{*}{ Mignon cracker flavor } & \multirow{2}{*}{ Characteristic aroma of Mignon cracker } & Weak: Mignon cracker - 70 \% aroma \\
\hline & & & Intense: Mignon cracker with $+30 \%$ aroma \\
\hline & Bread aroma & Aroma associated with the taste of bread. & $\begin{array}{l}\text { Weak: Brand } A \text { water and salt cracker } \\
\text { Intense: Brand B water and salt cracker }\end{array}$ \\
\hline \multirow{3}{*}{ 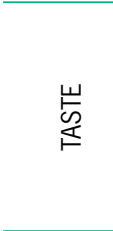 } & Salty Taste & Taste associated with the perception of salt & $\begin{array}{l}\text { Weak: Mignon cracker with }-80 \% \mathrm{NaCl} \\
\text { Intense: Mignon cracker with }+30 \% \mathrm{NaCl}\end{array}$ \\
\hline & Sweet taste & $\begin{array}{l}\text { Taste associated with the presence of } \\
\text { sweetness }\end{array}$ & $\begin{array}{l}\text { Weak: Mignon cracker with - } 30 \% \text { sugar } \\
\text { Intense: Mignon cracker with } 70 \% \text { sugar }\end{array}$ \\
\hline & Aftertaste (bitter or metallic residual) & $\begin{array}{l}\text { Taste related to bitter and / or metallic } \\
\text { residual }\end{array}$ & $\begin{array}{l}\text { Weak: Mignon cracker with } 20 \% \mathrm{KCl} \\
\text { Intense: Mignon cracker with } 60 \% \mathrm{KCl}\end{array}$ \\
\hline \multirow{2}{*}{ 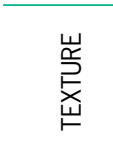 } & Hardness & $\begin{array}{l}\text { Strength to break the cracker with the incisor } \\
\text { teeth }\end{array}$ & $\begin{array}{l}\text { Little: Mignon cracker kept for } 4 \mathrm{~h} \text { at } 90.2 \% \mathrm{RH} \text { at } 25^{\circ} \mathrm{C} \\
\text { Much: Mignon cracker kept for } 12 \mathrm{~h} \text { in an oven at } 35^{\circ} \mathrm{C}\end{array}$ \\
\hline & Crunchiness & $\begin{array}{l}\text { Force exerted so that the product } \\
\text { disintegrates }\end{array}$ & $\begin{array}{l}\text { Little: Brand A Cream cracker } \\
\text { Much: Brand B Cream cracker }\end{array}$ \\
\hline
\end{tabular}

\section{Sensory profile of Mignon cracker sodium replaced}

The average results of each attribute for the evaluated formulations were submitted to the Levene test, all of which presented homogeneous variances $(p>0.05)$.
The formulations showed a significant difference $(p<$ $0.05)$ for the attributes of bread aroma, salty taste and sweet taste (Figure 4), and for the other attributes there was no significant difference.

For the bread aroma attribute, F2 and F6 presented the highest mean values (Figure 4) followed 


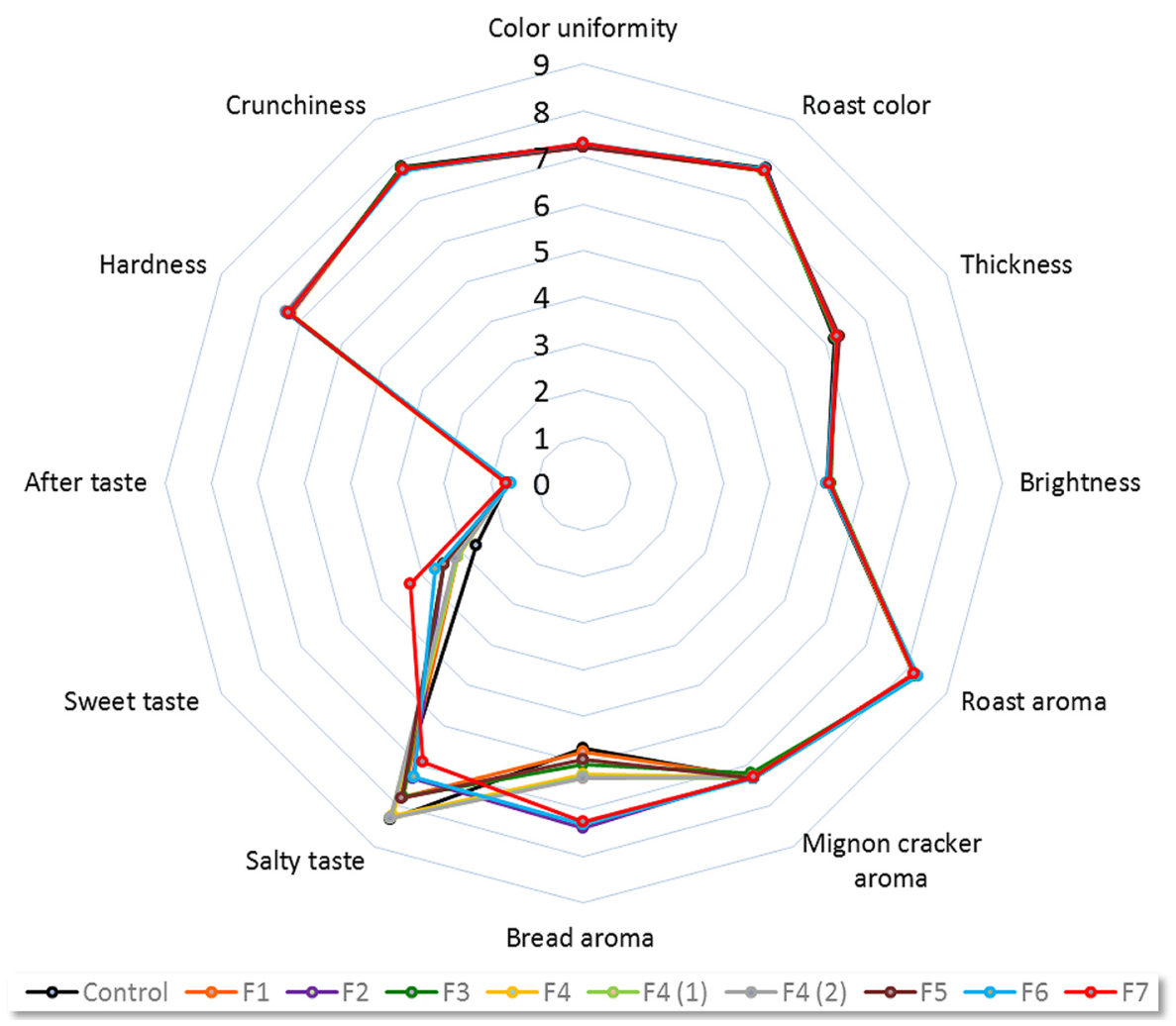

Figure 4 - Graphical representation (spider/radar chart) of the results from the quantitative descriptive analysis of the Mignon appetizer crackers.

by F7, which did not differ statistically $(p>0.05)$ from F6, which is related to the fact that F2, F6 and F7 have $30 \%$ of the PuraQ NA4 substitute. Moreover, PuraQ NA4 was confirmed as a flavor enhancer used to reduce sodium in foods, which, in addition, and adds a salty taste to the product intensifying other flavors (Corbion Puraq, 2013). Therefore, it can be considered that the addition of PuraQ NA4 $30 \%$ was responsible for the perception of greater bread aroma. Similarly, F3 and F5 had an addition of $15 \%$ PuraQ NA4 and did not differ statistically from each other $(p>0.05)$. F1 and control formulations had the lowest values for bread aroma, a result that is associated with the absence of PuraQ NA4 in the formulation.

As expected, the salty taste exhibited significant differences between samples. This was considered the key attribute, a descriptor of great industrial interest, where the control formulation presented the highest value and did not differ statistically $(p>0.05)$ from F4. It is important to highlight that the different $\mathrm{NaCl}$ substitution formulations, F1 (Nutek Salt 30 \%), F3 (Nutek Salt $15 \%$ and PuraQ NA4 $15 \%$ ) and F5 (Nutek Salt $30 \%$ and PuraQ NA4 $15 \%$ ), did not differ statistically $(p>0.05)$ from each other, which suggests that different combinations of $\mathrm{NaCl}$ and its substitutes provided the same perception of salty taste. Nevertheless, formulations F1 and F5 demonstrate that $\mathrm{KCl}$ is the substitute that best contributes to the salty taste since F3 presented a lower mean value than F1 and F5. F2 and F6 were statistically equal, although they have different substitution percentages. It can be seen that $\mathrm{F} 5$ and $\mathrm{F} 6$ (45 \% NaCl substitution) differed and F5 has a higher percentage of Nutek Salt in the formulation, which provided a more pronounced salty taste. F7 with $60 \% \mathrm{NaCl}$ replacement differed statistically $(p<0.05)$ from all samples with the lowest perception of salty taste.

In the spider or radar graph (Figure 4), the similarity between the samples for most attributes and the low values provided for aftertaste and sweet taste are clearly evident. For the sweet taste F7 $160 \% \mathrm{NaCl}$ substitution) presented a value which was significantly higher (approximately 3) than the other formulations followed by F6. Formulations F2, F3 and F5 were statistically equal $(p>0.05)$, followed by F1, F4 and their repetitions. The increase in sweet taste was directly related to the higher percentage of $\mathrm{NaCl}$ substitution, and was influenced by the combination of flavor enhancer substituents.

It is worth mentioning that where there was a significant difference $(p<0.05)$ F4 $(20 \%$ X2 and $20 \%$ X3) stood out from the others for presenting a salty taste equal to the control sample. It was evident that formulation F7 (30 \% X2 and $30 \%$ X3) showed the greatest differences when compared to the control formulation, in terms of increases in the sweet taste 
and bread aroma attribute and a reduction in the salty taste. However, the difference between the highest and lowest averages (between 6 and 9 points in the salty taste) did not exceed two points on the hedonic scale, demonstrating proximity between the results.

As for the appearance attributes, there was no significant difference between formulations, which is important as they avoid the visual impact on consumers during purchase. It was confirmed that an understanding of sensory properties of products with reduced sodium content is important, since the reduction in salinity triggers congruent effects such as an increased sensation of sweetness, which may influence characteristic aromas, appearance and texture (Raithatha, 2014).

\section{Multivariate exploratory assessment: PCA}

Quantitative Descriptive Analysis through Principal Component Analysis (PCA) identifies much of the study's variability (Figure 5). The first main component F1 was the source of $84.6 \%$ of the variability among the samples while the second axis (F2) accounted for an additional $11.5 \%$ of this variability, thereby explaining $96.1 \%$ of the total variability. These results indicated that the attributes had been selected properly in QDA, i.e., close to the sensory perception power of the assessors, which were able to convincingly distinguish the samples.

Formulation F4 and its repetitions showed greater intensity of "salty taste", being closer to the control sample, and descriptive terminology, namely, "roast color", "Mignon cracker aroma" and "roast aroma". The formulations F1, F3 and F5 showed similar characteristics and stand apart on account of their higher values in the "after taste" and "crispness" attributes. The F1 and F5 samples were closer to each other and both had $30 \%$ usage of Nutek Salt while F3 had $15 \%$ PuraQ NA4 and $15 \%$ Nutek Salt. Formulations F2 and F6 were similar and presented the highest averages for "color uniformity" and "bread aroma", and both samples show $30 \%$ of PuraQ NA4 associated with the greater intensity of the "bread aroma" attribute.

The F7 formulation was distinguished by its greater proximity to the "sweet taste", a fact already discussed previously. It can also be said that the "sweet taste" was negatively correlated with the "salty taste", corroborating the difference between control and F7. It is worth mentioning that even with $60 \%$ replacement, the F7 sample was not positively correlated with the aftertaste (bitter / metallic), contrary to what was observed in the formulation of breads with 50-75\% sodium replacement (Lynch et al., 2009).

\section{Acceptance and purchase intention}

Samples F4, F7 and Control were used in consumer tests as F4 formulation showed no difference for most attributes in relation to control, F7 as it had the lowest sodium content (< $699 \mathrm{mg} \mathrm{Na} 100 \mathrm{~g}^{1}$ of cracker), and the control formulation for being the reference sample (Table 4).

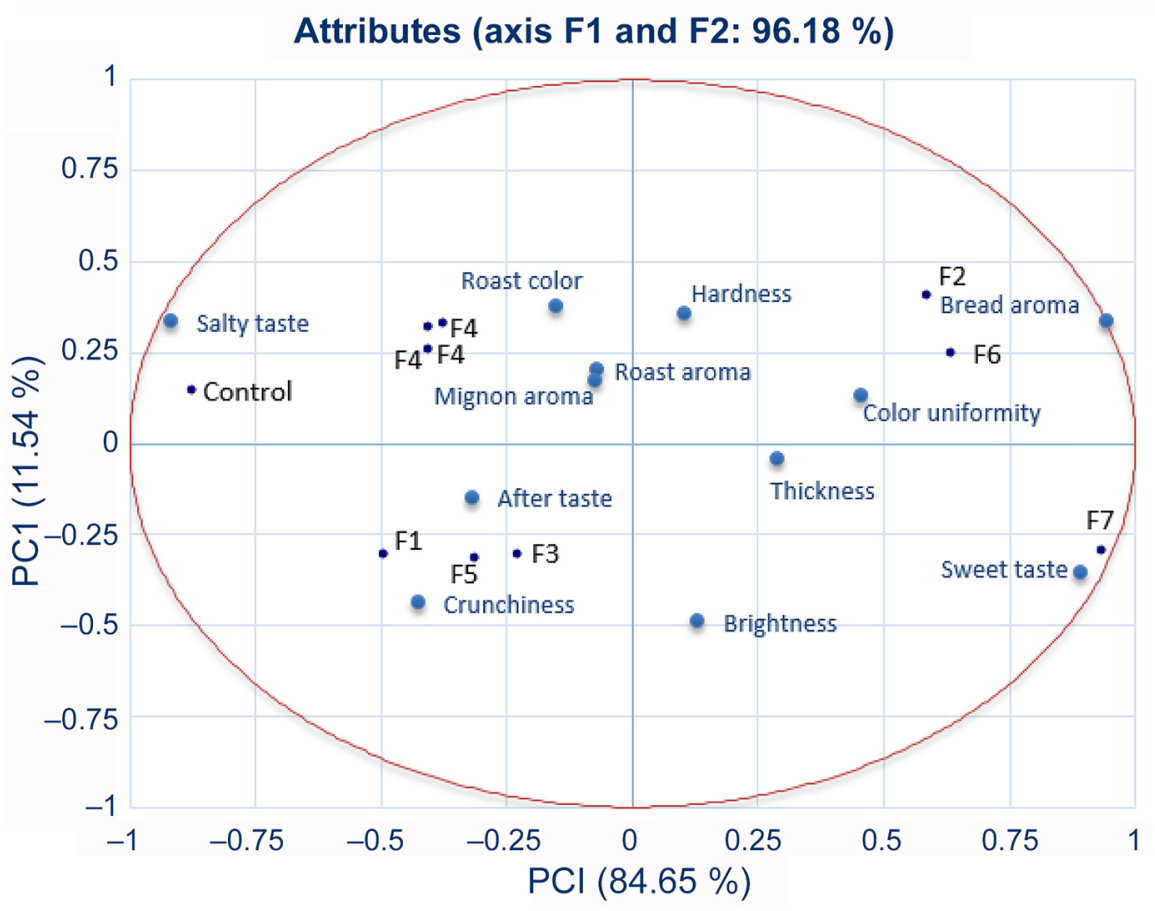

Figure 5 - Projection of attributes and formulations of sodium reduced crackers in the PCA of Quantitative Descriptive Analysis (QDA) data. 
Table 4 - Sensory attributes of Mignon crackers in the acceptance tests.

\begin{tabular}{lccc}
\hline \multirow{2}{*}{ Formulation } & \multicolumn{3}{c}{ Acceptance $^{\#}$} \\
\cline { 2 - 4 } & Taste & Overall quality & Purchase intention (\%) \\
\hline Control & $7.19 \pm 1.50^{\mathrm{a}}$ & $7.21 \pm 1.37^{\mathrm{a}}$ & 80.6 \\
F4 & $7.27 \pm 1.23^{\mathrm{a}}$ & $7.35 \pm 1.25^{\mathrm{a}}$ & 82.8 \\
F7 & $6.95 \pm 1.51^{\mathrm{a}}$ & $7.19 \pm 1.29^{\mathrm{a}}$ & 74.4 \\
\hline
\end{tabular}

\#values (mean \pm standard deviation) in the columns accompanied by equal letters do not differ from each other by the Tukey test $(p<0.05)$.

As for the acceptance, in relation to the overall quality and taste, the formulations did not differ significantly $(p<0.05)$ from each other, indicating that the substitutions of Nutek Salt and PuraQ NA4 for $\mathrm{NaCl}$ did not compromise the acceptance of the product by consumers. Thus, the replacement of up to $60 \% \mathrm{NaCl}$ by the substituents proposed in the percentages applied (max. $30 \%$ ), can be used by the industry, safe in the knowledge that it would not significantly influence acceptance.

In the preference test, the two formulations F4 (40 $\quad \begin{array}{lllllll}4 & \mathrm{NaCl} & \text { substitution}) ~ a n d ~ & \mathrm{~F} 7 & (60 & \% & \mathrm{NaCl}\end{array}$ substitution) scored more than $70 \%$ purchase intention, which is considered an adequate value (Dutcosky, 2013) for the acceptance criterion. The fact that the F4 sample had a higher percentage of purchase intention than the control sample, demonstrated that substitution, even at $40 \%$, can be carried out without changing the purchase intention of the appetizer-type Mignon cracker; moreover, there might be a possible preference increase.

The higher the replacement percentage, the greater the increase in the cost of cracker production, as sodium chloride has a relatively lower cost compared with the substitutes. To be more precise, Nutek Salt and flavor PuraQ NA4 ingredients raised fabrication costs by $5.0 \%$ and $7.5 \%$ comparing F4 and F7 with the control sample, respectively. Up to now, there have been no studies showing the cost of $\mathrm{NaCl}$ replacement by its industrial replacements. According to Busch et al. (2013), public awareness of healthiness is a major factor of success for the acceptance of a product with a higher cost, which encourages the type of replacement run in the present findings.

In the quest to have better consumer perception beyond the global projection, specific sensory modalities can help and lead to better discrimination. The masking of certain parameters to the detriment of others, can assist in specific assessments, as in studies with wine, where red light was used to mask differences in appearance or color (Smith and McSweeney, 2019). The red light influenced evaluations by the participants and affected the description of the tested products. Another way to improve the assessment is word association (WA) and the product personality profile (PPP), which can be used independently or complementarily (Gámbaro et al., 2019). WA provides information on the characteristics of the different formulations and the product's personality profile (PPP) gives information about the image consumers have of each product.

\section{Conclusions}

An effective sodium replacement was proposed on an industrial scale for the appetizer-type Mignon cracker. The optimization demonstrated that $\mathrm{KCl}$ (Nutek Salt) and flavor (PuraQ NA4) can be used to partially replace $\mathrm{NaCl}$ in the production of appetizer-type Mignon crackers, in partial substitutions up to $60 \%$ of $\mathrm{NaCl}$ without compromising the characteristics of hardness, sensory acceptance and purchase intention.

The reduction in sodium content with a $60 \%$ replacement reached the reference value of $699 \mathrm{mg}$ $\mathrm{Na} 100 \mathrm{~g}^{1}$ of cracker, and could therefore use the term "Reduced in Sodium" on the label according to the FDA, justified by the reduction of more than $50 \%$ in sodium content.

The Quantitative Descriptive Analysis (QDA) presented significant differences for the attributes "salty taste", "bread aroma" and "sweet taste" among the formulations. Multivariate analysis of Principal Components (PCA) explored similarity of samples, where formulation with $40 \%$ replacement was statistically equal $(p<0.05)$ to the control, for the attribute of greatest interest (salty taste). This formulation represents a $5.0 \%$ cost increase in the process, exemplifying an intermediate increase when compared to F7 (60\% replacement), with $7.5 \%$. In the acceptance test, there was no significant difference $(p<0.05)$ between control, F4 and F7 formulations for taste and overall quality. Finally, these two formulations showed more than $70 \%$ of purchase intention, demonstrating that minor differences perceived in QDA by trained assessors went unnoticed by consumers.

\section{Authors' Contributions}

Conceptualization: Pieta, F.; Pieta, A.; Burgardt, V.C.F.; Machado-Lunckes; Lucchetta, L. Data acquisition: Pieta, F.; Pieta, A. Data analysis: Pieta, F; Pieta, A. Design of methodology: Pieta, F.; Pieta, A.; Burgardt, V.C.F.; Prado, N.V.; Machado-Lunckes; Lucchetta, L. Writing and editing: Pieta, F.; Pieta, A.; Marques, C.; Burgardt, V.C.F.; Prado, N.V.; MachadoLunckes; Lucchetta, L.

\section{Acknowledgments}

Financial support from Parati Kellog's industry and Brazilian agencies to the development of research (Coordination for the Improvement of Higher Level Personnel (CAPES), Brazilian National Council for Scientific and Technological Development (CNPq) Araucaria Foundation). 


\section{References}

Antmann, G.; Ares, G.; Varela, P.; Salvador, A.; Coste, B.; Fiszman, S.M. 2011. Consumers' texture vocabulary: results from a free listing study in three Spanish-speaking countries. Food Quality and Preference 22: 165-172. https://doi. org/10.1016/j.foodqual.2010.09.007

Association of Official Analytical Chemists - International [AOAC]. 2005. Official Methods of Analysis. 18ed. AOAC, Gaithersburg, MD, USA.

Arepally, D.; Reddy, R.S.; Goswami, T.K.; Datta, A.K. 2020. Biscuit baking: a review. LWT - Food Science and Technology 131: 109726. https://doi.org/10.1016/j.lwt.2020.109726

Bassett, M.N.; Pérez-Palacios, T.; Cipriano, I.; Cardoso, P.; Ferreira, I.M.; Samman, N.; Pinho, O. 2014. Development of bread with $\mathrm{NaCl}$ reduction and calcium fortification: study of its quality characteristics. Journal of Food Quality 37: 107116. https://doi.org/10.1111/jfq.12079

Benincá, C.; Schneider, J.T.; Barros, I.R.; Nagata, N.; PeraltaZamora, P.; Zanoelo, E.F. 2018. Sodium content of salty biscuits marketed in Brazil: a benchmark study on the content of salt in processed foods and on consumer perceptions. Integrative Food, Nutrition and Metabolism 5: 1-8.

Benziger, C.P.; Roth, G.A.; Moran, A.E. 2016. The global burden of disease study and the preventable burden of NCD. Global Heart 11: 393. http://doi.org/10.1016/j.gheart.2016.10.024

Busch, J.L.H.C.; Yong, F.Y.S.; Goh, S.M. 2013. Sodium reduction: optimizing product composition and structure towards increasing saltiness perception. Trends in Food Science \& Technology 29: 21-34. https://doi.org/10.1016/j. tifs.2012.08.005

Cepanec, K.; Vugrinec, S.; Cvetković, T.; Ranilović, J. 2017. Potassium chloride-based salt substitutes: a critical review with a focus on the patent literature: potassium chloride-based salt substitutes. Comprehensive Reviews in Food Science and Food Safety 16: 881-894. https://doi.org/10.1111/15414337.12291

Chavan, R.S.; Sandeep, K.; Basu, S.; Bhatt, S. 2016. Biscuits, cookies, and crackers: chemistry and manufacture. p. 437444. In: Caballero, B.; Finglas, P.; Toldra, F. Encyclopedia of Food and Health. Elsevier, Amsterdam, The Netherlands. https://doi.org/10.1016/B978-0-12-384947-2.00076-3

Corbion Puraq. 2013. PuraQ Arome NA4: natural flavoring for reduced-sodium meat products. Available at: http://www. corbion.com/media/166736/puraqaromena4-useng-1013.pdf [Accessed Feb 24, 2020]

Dutcosky, S.D. 2013. Sensory Analysis of Food = Análise Sensorial de Alimentos. 4ed. PUC Press, Curitiba, PR, Brazil (in Portuguese).

Food and Drug Administration [FDA]. 2016. Draft Guidance for Industry: Voluntary Sodium Reduction Goals; Target Mean and Upper Bound Concentrations for Sodium in Commercially Processed, Packaged, and Prepared Foods. Food and Drug Administration, Washington, DC, USA.

Gámbaro, A.; Roascio, A.; Boinbaser, L.; Pérez, S.; Parente, E. 2019. Application of two projective techniques in the study of consumer perception of antiperspirant/deodorants. Journal of Sensory Studies 34: e12478. https://doi.org/10.1111/joss.12478
García-Gómez, B.; Romero-Rodríguez, Á.; Vázquez-Odériz, L.; Muñoz-Ferreiro, N.; Vázquez, M. 2019. Sensory quality and consumer acceptance of skim yoghurt produced with transglutaminase at pilot plant scale. International Journal of Dairy Technology 72: 388-394. https://doi.org/10.1111/14710307.12595

Granato, D.; Putnik, P.; Kovačević, D.B.; Santos, J.S.; Calado, V.; Rocha, R.S.; Cruz, A.G.; Jarvis, B.; Rodionova, O.Y.; Pomerantsev, A. 2018. Trends in chemometrics: food authentication, microbiology, and effects of processing. Comprehensive Reviews in Food Science and Food Safety 17: 663-677. https://doi.org/10.1111/1541-4337.12341

Hoffmann, W.; Luzzi, G.; Steffens, M.; Clawin-Rädecker, I.; Franz, C.M.A.P.; Fritsche, J. 2020. Salt reduction in filmripened, semihard Edam cheese. International Journal of Dairy Technology 73: 270-282. https:// doi.org/10.1111/14710307.12675

International Organization for Standardization [ISO]. 2004. ISO 16820 - Sensory Analysis - Methodology - Sequential Analysis. International Organization for Standardization [ISO]. 2012. ISO 8586 - Sensory Analysis - General Guidelines for the Selection, Training and Monitoring of Selected Assessors and Expert Sensory Assessors. ISO, Geneve, Switzerland.

International Organization for Standardization [ISO]. 2017a. ISO 13299 - Sensory Analysis - Methodology - General Guidance for Establishing a Sensory Profile. ISO, Geneve, Switzerland.

International Organization for Standardization [ISO]. 2017b. ISO 5492. Sensory Analysis - Vocabulary. ISO, Geneve, Switzerland.

Kanellos, M. 2012. Salt: a favorite ingredient gets a molecular makeover. Forbes. Sept. 5. https://www.forbes.com/sites/ michaelkanellos/2012/09/05/salt-a-favorite-ingredient-gets-amolecular-makeover/?sh =603fe0db7a35

Kitt, J.; Fox, R.; Tucker, K.L.; McManus, R.J. 2019. New approaches in hypertension management: a review of current and developing technologies and their potential impact on hypertension care. Current Hypertension Reports 21: 44. https://doi.org/10.1007/s11906-019-0949-4

Lynch, E.J.; Dal Bello, F.; Sheehan, E.M.; Cashman, K.D.; Arendt, E.K. 2009. Fundamental studies on the reduction of salt on dough and bread characteristics. Food Research International 42: 885-891. https://doi.org/10.1016/j.foodres.2009.03.014

Mesías, M.; Holgado, F.; Márquez-Ruiz, G.; Morales, F.J. 2015. Effect of sodium replacement in cookies on the formation of process contaminants and lipid oxidation. LWT - Food Science and Technology 62: 633-639. https://doi.org/10.1016/j. lwt.2014.11.028

Raithatha, C. 2014. The role of sensory perception and sensory evaluation in the development of reduced sodium foods. Agro Food Industry Hi Tech 25: 48-52.

Santos, F.F.D.; Dantas, N.M.; Simoni, N.K.; Pontes, L.S.; Silva, M.E.M.P. 2020. Are foods naturally rich in glutamic acid an alternative to sodium reduction? Food Science and Technology 40: 190-196. https://doi.org/10.1590/fst.08819

Seganfredo, D.; Rodrigues, S.; Kalschne, D.L.; Sarmento, C.M.P.; Canan, C. 2016. Partial substitution of sodium chloride in Toscana sausages and the effect on product characteristics. Semina: Ciências Agrárias 37: 1285. https://doi. org/10.5433/1679-0359.2016v37n3p1285 
Silva, H.L.A.; Balthazar, C.F.; Silva, R.; Vieira, A.H.; Costa, R.G.B.; Esmerino, E.A.; Freitas, M.Q.; Cruz, A.G. 2018. Sodium reduction and flavor enhancer addition in probiotic prato cheese: contributions of quantitative descriptive analysis and temporal dominance of sensations for sensory profiling. Journal of Dairy Science 10: 8837-8846. https://doi. org/10.3168/jds.2018-14819

Smith, A.M.; McSweeney, M.B. 2019. Partial projective mapping and ultra-flash profile with and without red light: a case study with white wine. Journal of Sensory Studies 34: e12528. https://doi.org/10.1111/joss. 12528

Souza, A.M.; Bezerra, I.N.; Pereira, R.A.; Peterson, K.E.; Sichieri, R. 2013. Dietary sources of sodium intake in Brazil in 20082009. Journal of the Academy of Nutrition and Dietetics 113: 1359-1365. https://doi.org/10.1016/j.jand.2013.04.023

Stable Micro Systems. 2000. BIS2/KB - TA-XT2 Application Study: Biscuits/Cookies. Stable Micro Systems, Surrey, UK.

Stone, H.; Sidel, J.L. 2004. Descriptive Analysis. p. 201-245. In: Sensory Evaluation Practices. Elsevier, Amsterdam, The Netherlands. https://doi.org/10.1016/B978-0126726909/50010-X
Taylor, C.; Doyle, M.; Webb, D. 2018. The safety of sodium reduction in the food supply: A cross-discipline balancing act. Critical Reviews in Food Science and Nutrition 58: 1650-1659. https://doi.org/10.1080/10408398.2016.1276431

Vidal, V.A.; Santana, J.B.; Paglarini, C.S.; Silva, M.A.; Freitas, M.Q.; Esmerino, E.A.; Crus, A.G.; Pollonio, M.A. 2020. Adding lysine and yeast extract improves sensory properties of low sodium salted meat. Meat Science 159: 107911. https:// doi.org/10.1016/j.meatsci.2019.107911

Worch, T.; Lê, S.; Punter, P. 2010. How reliable are the consumers? Comparison of sensory profiles from consumers and experts. Food Quality and Preference 21: 309-318. https:// doi.org/10.1016/j.foodqual.2009.06.001

World Health Organization [WHO]. 2002. Reducing Risks, Promoting Healthy Life. WHO, Geneve, Switzerland.

World Health Organization [WHO]. 2010. Global Status Report on Non-Communicable Diseases. WHO, Geneve, Switzerland.

World Health Organization [WHO]. 2016. Guideline: Sodium Intake for Adults and Children. WHO, Geneve, Switzerland. 